This item was submitted to Loughborough's Research Repository by the author.

Items in Figshare are protected by copyright, with all rights reserved, unless otherwise indicated.

\title{
A simplified model of the reflow soldering process
}

PLEASE CITE THE PUBLISHED VERSION

PUBLISHER

(C) IEEE

LICENCE

CC BY-NC-ND 4.0

REPOSITORY RECORD

Whalley, David C.. 2019. "A Simplified Model of the Reflow Soldering Process". figshare. https://hdl.handle.net/2134/3978. 
This item was submitted to Loughborough's Institutional Repository (https://dspace.lboro.ac.uk/) by the author and is made available under the following Creative Commons Licence conditions.

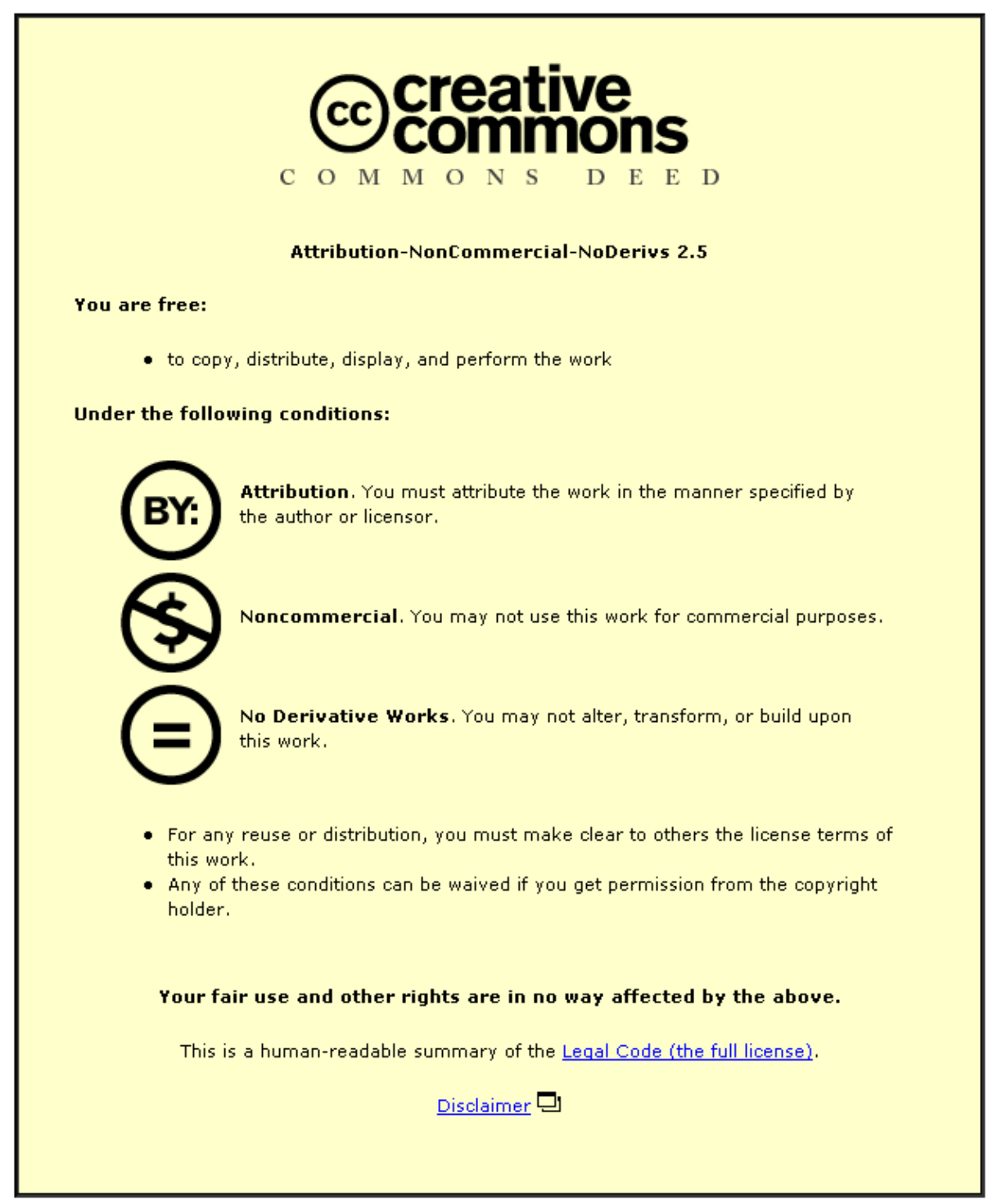

For the full text of this licence, please go to: http://creativecommons.org/licenses/by-nc-nd/2.5/ 


\title{
A SIMPLIFIED MODEL OF THE REFLOW SOLDERING PROCESS
}

\author{
David C. Whalley \\ Wolfson School of Mechanical and Manufacturing Engineering \\ Loughborough University, Leicestershire, LE11 3TU, UK \\ Phone: +44-1509-267721 \\ Fax: +44-1509-267748 \\ Email: D.C.Whalley@Lboro.ac.uk
}

\begin{abstract}
Previous models of the reflow soldering process have used commercial finite difference (FD) or computational fluid dynamics simulation software to create detailed representations of the product and/or the reflow furnace. Such models have been shown to be highly accurate at predicting the temperatures a PCB design will achieve during the reflow process. These models are however complex to generate and analysis times are long, even using modern high performance workstations. With the move to adopt lead free soldering technology, and the consequently higher reflow process temperatures, optimisation of the reflow profile is gaining a renewed emphasis. This paper describes a less complex approach to modelling of the process, which uses simplified representations of both the product and the process, together with a FD solver developed specifically for this application, and which achieves an accuracy comparable with more detailed models. In order to establish an accurate representation of the specific reflow furnace being simulated, a reflow logger is used to make measurements of the temperature and level of thermal convection at each point along the length of the furnace for a small number of carefully chosen reflow profiles. The temperatures for any other reflow profile can then be predicted from these measurements.
\end{abstract}

KEY WORDS: Solder, simulation, temperature profile

\section{NOMENCLATURE}
A area, $\mathrm{m}^{2}$
C heat capacity, $\mathrm{J} / \mathrm{kgK}$
EA nodal plan area, $\mathrm{m}^{2}$
$\mathrm{F}_{\mathrm{C}}$ convective flux into $\mathrm{PCB}$ node, $\mathrm{W}$
$F_{R}$ radiative flux into $P C B$ node, $W$
$\mathrm{F}_{\mathrm{K}}$ resistive flux between a node and all adjacent nodes, $\mathrm{W}$
$\mathrm{H}(\mathrm{x})$ convective constant for position $\mathrm{x}$ in furnace, $\mathrm{W} / \mathrm{m}^{2} \mathrm{~K}$
$\mathrm{K}$ thermal conductivity, $\mathrm{W} / \mathrm{mK}$
Q net heat flux into node or sensor, W
$\mathrm{Q}_{\mathrm{C}}$ convective flux into sensor, $\mathrm{W}$
$\mathrm{Q}_{\mathrm{R}}$ radiative flux into sensor, $\mathrm{W}$
$\mathrm{R}$ thermal resistance, ${ }^{\circ} \mathrm{C} / \mathrm{W}$
SA total surface area of a node, $\mathrm{m}^{2}$
$\mathrm{SP}_{\mathrm{n}}$ set point temperature of zone $\mathrm{n},{ }^{\circ} \mathrm{C}$
$\mathrm{t}$ time, $\mathrm{s}$

$\mathrm{T}$ nodal temperature, ${ }^{\circ} \mathrm{C}$

$\mathrm{T}_{\mathrm{H}} \quad$ air/heater panel temperature in furnace, ${ }^{\circ} \mathrm{C}$

$\mathrm{T}_{\mathrm{s}} \quad$ sensor temperature, ${ }^{\circ} \mathrm{C}$

$\mathrm{x}$ location along the furnace length, $\mathrm{m}$

$\mathrm{X}$ length of a node, $\mathrm{m}$

$\mathrm{Y}$ width of a node, $\mathrm{m}$

$\mathrm{Z}$ thickness of the PCB, $\mathrm{m}$

$\varepsilon_{\mathrm{E}} \quad$ effective average emissivity of a node

$\varepsilon_{\mathrm{H}}(\mathrm{x})$ effective average heater panel emissivity at position $\mathrm{x}$

$\Delta \mathrm{t} \quad$ time step, $\mathrm{s}$

$\sigma \quad$ radiation absorption constant for node

$\zeta \quad$ Stephan Boltzmann constant, $\mathrm{W} / \mathrm{m}^{2} \mathrm{~K}^{4}$

\section{INTRODUCTION}

Infra-red and convection reflow are non-equilibrium processes in that the product temperature is never in thermal equilibrium with that of the heat source. The reflow furnace process settings must therefore be tailored to each individual product design in order to ensure the optimum time/temperature profile for that particular PCB assembly. In recent years there has been a transition from earlier designs of reflow furnace, where radiation was the dominant heat transfer mechanism, to more modern designs where convective heat transfer dominates. The higher level of heat transfer achievable with a convection dominant furnace has reduced variations in the temperature profile between different products and also the spread in the temperatures within an individual product. These have consequently increased the process window. The accelerating transition to lead free soldering processes will however reduce the process window, thereby placing renewed emphasis on techniques for reflow profile optimisation.

The standard approach to reflow profile set-up has been to attach a number of thermocouples to an example of the product to be assembled, with the choice of thermocouple location being based on a combination of engineering judgement and experience of similar products and component package types. The product is then passed through the reflow furnace with a "first guess" set of process temperatures while a data logger records the temperatures measured by the thermocouples. The initial process settings are then modified until the required profile is obtained. This profile modification process can be assisted by very simplified models of the process, such as those within existing commercial reflow 
profiler software packages. The use of such software reduces the number of iterations before the required profile is obtained, but does not eliminate the initial instrumented reflow process run using an example of the new product.

A computational model of the process has the potential to entirely eliminate this on-line set-up procedure through the construction of a model of the product using the PCB CAD data, and could even be used to ensure the compatibility of a PCB design with the reflow process before it is released to manufacture. Such a model can also eliminate the risk that the chosen thermocouple locations do not cover the full spread of reflow profiles within the product. The feasibility of such models was demonstrated by Whalley et al. [1,2] and Sarvar and Conway [3] showed the high level of accuracy obtainable, provided accurate materials properties were available. Other approaches to simulation of the process has also been reported e.g. by Eftychiou et al. [4] and Kim et al. [5] who have developed two dimensional fluid flow models of the process, and $\mathrm{Yu}$ and Kivilathi [6] who have developed a 3D fluid flow model. Similar thermal processes in the ceramics industry have also been simulated by, for example, Hurst and Pulko [7] but this type of product is generally composed of a single material and both product and furnace are geometrically less complex.

There are however a number of disadvantages to the modelling techniques described by Whalley and Sarvar. The principal of these disadvantages are the necessity of constructing a detailed physical description of the specific reflow furnace to be modelled and the long analysis time due to the large number of individual thermal conductances and masses forming the model. The description of the reflow furnace has required detailed measurements of the geometry of each zone within the furnace and the measurement of the airflow velocity incident on the PCB throughout the furnace. The analysis time even on a high performance workstation has been found to be in the order of tens of minutes for even a moderately complex PCB design. This might be acceptable if the model only has to be run a small number of times for a specific product, but is not compatible with algorithms designed to automatically search for the optimum process settings, as these typically require a very large number of modelling iterations.

Whalley and Hyslop [8] reported a modified approach to the modelling of the reflow process, which uses a simple two dimensional (2D) model of the PCB assembly. This paper describes a simple model of the temperature and heat transfer properties (convective and radiative) at any position along the length of the Reflow furnace. This avoids the need to create a detailed physical description of the reflow furnace by using simple sensors to measure the furnace's heat transfer performance. This furnace model can then be used together with the simple 2D model of the PCB in a solver constructed specifically for the application and which is therefore highly efficient. Analysis times in the order of a fraction of a second are consequently achievable using a typical PC running under the Microsoft Windows operating system.

\section{THE SIMPLIFIED SOLVER}

In representing the PCB assembly with a $2 \mathrm{D}$ model it is assumed that there is no significant variation in temperature through the thickness of the PCB. This assumption is based on the low Biot number, $B i$, associated with heat transfer through the PCB thickness. The Biot number is the ratio of the internal thermal resistance to the external thermal resistance and if significantly less than one indicates that internal temperature gradients will be small. For a uniform slab of material having a thickness $\mathrm{Z}$ and thermal conductivity $\mathrm{K}$ which is heated from both sides with a heat transfer coefficient of $\mathrm{H}$, the Biot number is given by:

$B i=\frac{H \times Z}{2 \times K}$

For a typical PCB having a thickness of $1.6 \mathrm{~mm}$ and a $\mathrm{K}$ of around $0.31 \mathrm{~W} / \mathrm{m} . \mathrm{K}$, and for a typical average heat transfer coefficient for a convection reflow process of $50 \mathrm{~W} / \mathrm{m}^{2} . \mathrm{K}$, the Biot number is therefore only 0.129.

It is also assumed in the model that there is no variation in temperature between the components and the underlying area of the PCB. This assumption is more difficult to justify, but is in general supported by the results reported by Sarvar and Conway [3] and by the success of the approach being reported here. For components with a large thermal mass and which are poorly connected thermally to the PCB this assumption may break down and care will be necessary in developing the required library data for such components.

General purpose finite element/finite volume analysis software are able to employ a variety of element shapes and sizes in order to mesh the region of interest. The solver described here is however based on a uniform recti-linear grid of elements in order to maintain simplicity, high execution speed and easy presentation of results. Each element contains a central node, to which all of the thermal mass of that area of the assembly is assigned. The nodes are then interconnected by thermal conductances. If the time steps chosen are small enough that the boundary conditions and materials properties can be assumed to remain constant over the time step then the basic formulae to be solved at each node can be based on an explicit time integration approach and for each time iteration is:

$T_{t+\Delta t}=T_{t}+\frac{Q}{C} \times \Delta t$

where $T$ is the nodal temperature $(\mathrm{K}), t$ is time (s), $\Delta t$ is the time step (s), $Q$ is the net heat flux into the node (W) and $C$ is the heat capacity of the node $(\mathrm{J} / \mathrm{K})$. The average rate of change of temperature is typically less than $\pm 1^{\circ} \mathrm{C} / \mathrm{s}$ and the maximum rate of change seldom exceeds $\pm 5^{\circ} \mathrm{C} / \mathrm{s}$. A value of $\Delta t$ of $1 \mathrm{~s}$ therefore results in a stable solution with minimal changes in the materials properties and boundary conditions over a time step, and is also compatible with typical data acquisition rates for reflow data loggers.

The net heat flux into the node is the sum of the convective flux, $F_{C}$, and radiative flux, $F_{R}$, through the top and bottom 
surfaces, and the total conductive flux $F_{K}$ from the four adjacent nodes, i.e.:

$Q=F_{C}+F_{R}+F_{K}$

The convective flux, $F_{c}$, is a function of the difference in temperature between the node and the air temperature at the current location, $x$, within the furnace, and also of the heat transfer coefficient, which will depend on the incident air velocity at that location:

$$
F_{C}=\left(T_{H}(x)-T_{t}\right) \times H(x) \times S A
$$

where $T_{H}$ is the air/heater panel temperature $(\mathrm{K}), H(x)$ is the convective constant for position $x\left(\mathrm{~W} / \mathrm{m}^{2} . \mathrm{K}\right)$ and $S A$ is the total surface area for the node $\left(\mathrm{m}^{2}\right)$.

The radiative flux, $\mathrm{F}_{\mathrm{r}}$, is given by:

$$
F_{R}=\left(T_{H}(x)^{4}-T_{t}^{4}\right) \times \varepsilon_{H}(x) \times \sigma
$$

where $\varepsilon_{H}(x)$ is the effective average heater panel emissivity at position $x$, and $\sigma$ is the radiation absorption constant for the node, i.e.:

$$
\sigma=\varepsilon_{E} \times E A \times \zeta
$$

where $\varepsilon_{E}$ is the effective average emissivity of the PCB assembly over the node, $\mathrm{E} A$ is the nodal plan area, and $\zeta$ is the Stephan Boltzmann constant $\left(3.74 \times 10^{-16} \mathrm{~W} \mathrm{~m}^{-2} \mathrm{~K}^{-4}\right)$.

Provided the heights of the components are small in relation to the dimensions of the thermal nodes then they will not significantly increase the effective area of the node absorbing radiation, but they will increase its effective emissivity although this effect is complex to calculate. Inter-node shadowing due to tall components is also complex to evaluate accurately and this approach assumes that it is negligible.

The total conductive flux, $F_{k}$, is the sum of the four fluxes to/from the adjacent nodes (three or two adjacent nodes for edge or corner nodes respectively:

$$
\mathrm{F}_{\mathrm{K}}=\sum_{x=+/-1 ; y=+/-1 ;} \frac{\left(T_{t}(x, y)-T_{t}\right)}{R(x, y)}
$$

where $T_{t}(x, y)$ is the nodal temperature for adjacent nodes, $R(x, y)$ is the thermal resistance between the node and adjacent node $x, y(\mathrm{~K} / \mathrm{W})$.

The thermal resistance from the centre of any element to its edge is calculated as follows:

$$
\begin{aligned}
& R_{X}=\frac{X}{2 \times K \times Y \times Z} \\
& R_{Y}=\frac{Y}{2 \times K \times X \times Z}
\end{aligned}
$$

Where $\mathrm{X}$ and $\mathrm{Y}$ are the in plane dimensions of the node, $\mathrm{Z}$ is its thickness and $\mathrm{K}$ its effective in plane thermal conductivity.

These node centre to edge thermal resistances are calculated for each node and then added to those for each adjacent node to give the node centre to centre resistances.
A programme to iteratively solve the above equations has been implemented in $\mathrm{C}++$. The executable is only $370 \mathrm{kB}$ including an animated graphical display of the predicted PCB temperatures. Input and output files use a comma separated variable (CSV) format for ease of export/import to/from other software such as spreadsheet programs.

\section{GENERATION OF THE OVEN MODEL}

A reflow furnace profile is often thought of as consisting of a number of zones of uniform temperature with step changes in temperature at the boundaries between zones as shown in Figure 1. Any real oven will however depart from this idealised view in a number of ways as is also shown in Figure 1. Firstly, there will be some degree of error between the oven set points and the actual heater panel temperature. There may also be some variation in heater panel temperature within a zone and the zones will interact to some extent, meaning that the transition from one zone to the next is not instantaneous. The sharpness of this transition between zones is dependant on various factors such as the tunnel height and the details of the air flow velocity distributions. There are also areas of the furnace that are not under active temperature control, typically gaps between zones used for conveyor supports and the entrance and exit areas, which nevertheless may be significant to the overall reflow profile. A method to determine the real process temperatures at any point in the furnace, and as a function of the process recipe, must therefore be established.

The oven model used in the solver consists of a set of the three parameters, heater/air temperature, $T_{H}$, heater emissivity, $\varepsilon_{H}$, and convection coefficient, $H$, at closely spaced intervals along the length of the conveyor. It is assumed that there is no variation in these parameters across the width of the conveyor. A method is therefore also required to measure $H$ and $\varepsilon_{H}$, which generally will not change significantly from recipe to recipe, as well as to predict the parameters $T_{H}$. The following section describes a procedure for deriving these parameters from measurements made using a calibration artefact. This artefact is passed through the reflow process using a strictly limited number of specific recipes to obtain the data required.

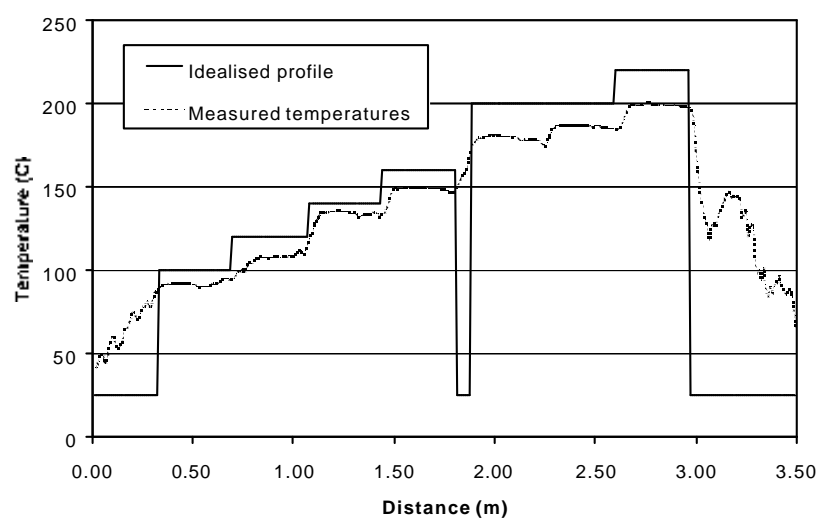

Figure 1. Comparison of an idealised furnace temperature profile with the measured temperatures 
Equations for the calibration artefact temperature response

Any temperature sensor used to derive the required information will have a thermal mass, $C$, and will absorb heat at a rate $Q$. Assuming that the sensor is constructed such that there is no significant conductive heat flow to/from it and that it is thermally conductive enough that there is a negligible internal temperature gradient, then the rate of change of temperature, $d T_{s} / d t$, recorded by the sensor will be:

$$
\frac{d T_{s}}{d t}=\frac{Q}{C}
$$

The total heat flux, $Q$, is a combination of radiative and convective fluxes and will depend on the difference in temperature between the sensor and the oven, the sensor area, the emissivity of both the sensor and of the oven components, and the convective heat transfer co-efficient between the oven atmosphere and the sensor:

$Q=Q_{C}+Q_{R}$

where, $Q_{C}$ is the convective flux:

$Q_{C}=\left(T_{H}-T_{s}\right) \times H \times A_{s}$

where, $T_{H}$ is the heater temperature, $\mathrm{H}$ is the convection coefficient and $\mathrm{A}_{\mathrm{s}}$ is the sensor surface area.

And $Q_{R}$ is the radiative flux:

$Q_{R}=\left(T_{H}{ }^{4}-T_{s}{ }^{4}\right) \times \varepsilon_{H} \times \varepsilon_{s} \times \zeta$

where $\varepsilon_{s}$ is the sensor emmissivity.

Combining equations 10 to 13 the overall temperature response of the sensor is therefore:

$\frac{d T_{s}}{d t}=\frac{\left[\left(T_{H}-T_{s}\right) \times H \times A_{s}\right]+\left[\left(T_{H}{ }^{4}-T_{s}{ }^{4}\right) \times \varepsilon_{H} \times \varepsilon_{s} \times \zeta\right]}{C}$

If an appropriately designed sensor, which is well characterised for its thermal mass, area and emissivity, is used to measure $\mathrm{T}_{\mathrm{s}}$ and $\mathrm{dT}_{\mathrm{s}} / \mathrm{dt}$ at three different temperature settings for each oven zone, then the three unknowns in equation 13, $\mathrm{T}_{\mathrm{H}}, \mathrm{H}$ and $\varepsilon_{\mathrm{H}}$, should in principal be obtainable by assembling and solving a set of three simultaneous equations. However this approach, in addition to the complexity of solving these equations, is likely to require large changes in the oven set points in order to isolate the radiative heat transfer from the convective and would also make it more difficult to isolate interactions between adjacent zone set points during the transition between zones. A minimum of four, and possibly more, separate runs would therefore be necessary in order to fully characterise the process.

An alternative approach is to use three sensors, each with a different combination of $\mathrm{C}, \mathrm{A}$ and $\varepsilon$ with which the three parameters could be derived with only one run through the furnace. To simplify data analysis the three sensors could be chosen so that they each have a different combination of extreme values for their $\mathrm{C}$ and $\varepsilon$ parameters, i.e.:
Sensor 2: High C, high $\varepsilon$

Sensor 3: High $\mathrm{C}$, low $\varepsilon$

Sensor 1 would closely track the oven air temperature, directly providing $\mathrm{T}_{\mathrm{H}}$, whilst the data from sensor 3 would, in combination with $\mathrm{T}_{\mathrm{H}}$, provide the $\mathrm{H}$ data by solving a version of equation 13 with the radiative term removed, i.e.:

$$
\frac{d T_{s}}{d t}=\frac{\left(T_{H}-T_{s}\right) \times H \times A_{s}}{C}
$$

The oven emissivity could then be obtained by solving equation 14 using the data obtained from sensor 2.

The disadvantage with this pproach is the more complex sensor set-up and the number of data logger channels used, reducing the opportunity for measuring differences side to side and top to bottom within the oven.

Further runs through the oven for different process settings would then allow the relationship between the set-points and the effective heater temperature to be established as is explained in the next section.

\section{Prediction of $\mathbf{T}_{\mathrm{H}}$ as a function of $\mathbf{x}$ for any process recipe}

Assuming that the oven emissivity does not vary significantly with the process settings, and that the convection coefficient also does not vary significantly unless specifically controllable by a fan speed controller, then the values for them derived from the artefact should be directly usable for any process recipe. The $\mathrm{T}_{\mathrm{H}}$ however will have to be predicted for any recipe not used for the calibration process. The calibration process will therefore have to be able to extract enough data to predict for every location in the oven the relationship between the set points for the current and the nearest adjacent zones, and $\mathrm{T}_{\mathrm{H}}$. This will have to also include "passive" zones, i.e. areas of the oven not within a controlled zone, but which will contribute to heat transfer. As noted earlier this includes gaps between zones, for example for conveyor supports, and the entrance and exit tunnels.

Rather than attempt to apply any more detailed knowledge of the design of the oven than is typically captured within a reflow data logger, i.e. the starting point and length of each zone, it is assumed that the influence of each zone extends half way into the next zone, except for the first and last (controllable) zones, whose influence are assumed to extend to the ends of the oven. For two typical zones, $Z_{n} \& Z_{n+1}$, with set points of $\mathrm{SP}_{\mathrm{n}}$ and $\mathrm{SP}_{\mathrm{n}+1}$ and which extend from $\mathrm{x}_{\mathrm{n}}$ to $\mathrm{x}_{\mathrm{n}+1}$ and $x_{n+1}$ to $x_{n+2}$ respectively, then $T_{H}$ would be calculated as a function of $\mathrm{SP}_{\mathrm{n}}$ and $\mathrm{SP}_{\mathrm{n}+1}$ between $\left(\mathrm{x}_{\mathrm{n}}+\mathrm{x}_{\mathrm{n}+1} / 2\right)$ and $\left(\mathrm{x}_{\mathrm{n}+1}+\right.$ $\left.x_{n+2} / 2\right)$. At the extremes of this range it is expected that $T_{H}$ would be almost entirely (linearly) dependent on the set point of one zone, but there may be differences in both scale and offset between the two, i.e.:

$\mathrm{T}_{\mathrm{H}}\left(\mathrm{x}_{\mathrm{n}}+\mathrm{x}_{\mathrm{n}+1} / 2\right)=\mathrm{a} \times \mathrm{SP}_{\mathrm{n}}+\mathrm{b}$

and

$\mathrm{T}_{\mathrm{H}}\left(\mathrm{x}_{\mathrm{n}+1}+\mathrm{x}_{\mathrm{n}+2} / 2\right)=\mathrm{c} \times \mathrm{SP}_{\mathrm{n}+1}+d$

Sensor 1: Low $\mathrm{C}$, high $\varepsilon$ 
where $a, b, c$ and d are the scale and offset errors for each zone.

For any point between these two extremes $\mathrm{T}_{\mathrm{H}}$ would be a function of both set points i.e.:

$\mathrm{T}_{\mathrm{H}}(\mathrm{x})=\mathrm{e}\left(\mathrm{a} \times \mathrm{SP}_{\mathrm{n}}+\mathrm{b}\right)+(1-\mathrm{e}) \times\left(\mathrm{c} \times \mathrm{SP}_{\mathrm{n}+1}+\mathrm{d}\right)$

where $\mathrm{e}$ is the proportionate contribution to $\mathrm{T}_{\mathrm{H}}$ from the two zone temperatures.

However equation 18 can be reduced to:

$\mathrm{T}_{\mathrm{H}}(\mathrm{x})=\mathrm{f} \times \mathrm{SP}_{\mathrm{n}}+\mathrm{g} \times \mathrm{SP}_{\mathrm{n}+1}+\mathrm{h}$

where the constants $\mathrm{f}, \mathrm{g}$ and $\mathrm{h}$ must be obtained from at least three runs through the oven for different combinations of $\mathrm{SP}_{\mathrm{n}}$ and $\mathrm{SP}_{\mathrm{n}+1}$ (although for some well calibrated ovens $\mathrm{h}$ may be very small).

If the oven has zones for which the level of convection is controllable then this process will have to be extended to include a prediction of $\mathrm{H}$ at each location. Additional calibration runs may also have to be made to capture this data.

\section{Artefact construction and trials}

For the purposes of testing the furnace calibration process described above, a calibration artefact was created based on a Datapaq Surveyor data logger carrier frame. This artefact consisted of a bare thermocouple projecting forward from the frame to act as sensor 1 and two further thermocouples attached to $18 \mathrm{~mm}$ diameter nickel alloy disks to act as sensors 2 and 3. One of these disks (sensor 2) was given a matt black coating to give a high emissivity and the other (sensor 3 ) had a highly polished finish to give a low emissivity. These sensors were supported only by the thermocouple wires, so there was negligible conductive heat transfer to/from them. This artefact was run through a Quad QRS7 furnace a total of four times, using the recipes listed in table 1 . Figure 2 shows the measured $\mathrm{T}_{\mathrm{H}}$ values for recipes $\mathrm{A}, \mathrm{B}$ and $\mathrm{C}$, and Figure 3 shows a comparison of the predicted values of $T_{H}$ for recipe $D$ with those measured. These results show that a reasonably good prediction of the $\mathrm{T}_{\mathrm{H}}$ values can be obtained.

Table 1. Process recipes used for the trials

\begin{tabular}{ccccc}
\hline \multirow{2}{*}{$\begin{array}{c}\text { Zone } \\
\text { Number }\end{array}$} & \multicolumn{4}{c}{ Recipe name/temperatures $\left({ }^{\circ} \mathrm{C}\right)$} \\
\cline { 2 - 5 } & $\mathrm{A}$ & $\mathrm{B}$ & $\mathrm{C}$ & $\mathrm{D}$ \\
\hline 1 & 100 & 100 & 80 & 90 \\
2 & 120 & 100 & 100 & 120 \\
3 & 140 & 140 & 120 & 150 \\
4 & 160 & 140 & 140 & 150 \\
5 & 200 & 200 & 180 & 190 \\
6 & 200 & 180 & 180 & 200 \\
7 & 220 & 220 & 200 & 230 \\
\hline
\end{tabular}

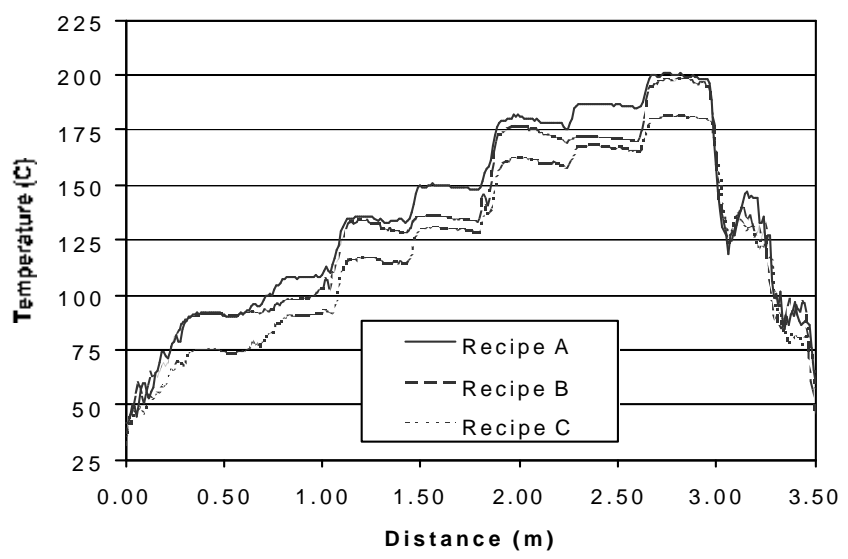

Figure 2. Measured process temperatures

Figure 4 shows the measured air temperatures and convection sensor (sensor 3) temperatures along the furnace length for recipe $\mathrm{B}$. It was found that the values of convective heat transfer coefficient calculated using equation 10 appeared very noisy. This was initially believed to be primarily due to a combination of noise in the temperature measurements and their resolution. Averaging of the $\mathrm{H}$ values over several seconds reduced this noise, however comparison of the $\mathrm{H}$ values calculated from three runs through the furnace showed that the remaining "noise" was fairly repeatable from run to run and is therefore concluded to be due to real spatial fluctuations of the air flows within the furnace. Figure 5 shows calculated values for $\mathrm{H}$ including averaging.

Although a difference in temperature between sensors 2 and 3 could be observed, the extraction of oven emissivity data is based on the relative slopes of these two curves, which differ only slightly. The resulting calculated emissivity values were therefore so noisy that even after significant averaging they were not useful. In fact the calculated values fluctuated below 0 and above 1, which is clearly not realistic. A heater emissivity, $\varepsilon_{\mathrm{H}}$, of 1 was therefore assumed for the whole furnace length.

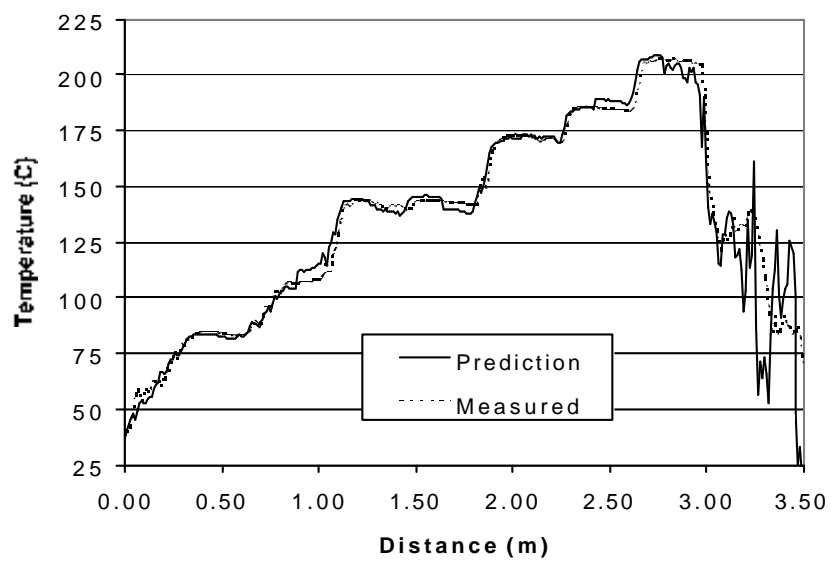

Figure 3. Comparison of measured and predicted process temperatures for recipe $\mathrm{D}$ 


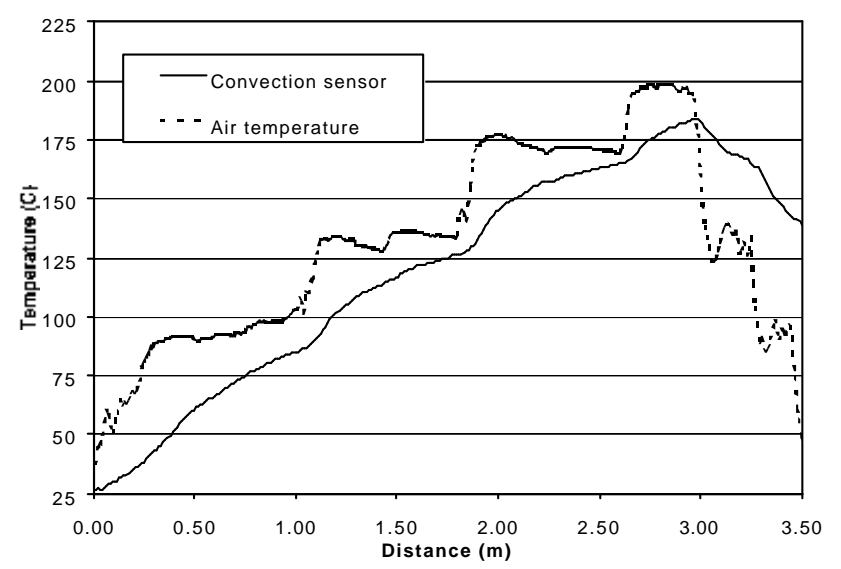

Figure 4. H sensor temperature measurements

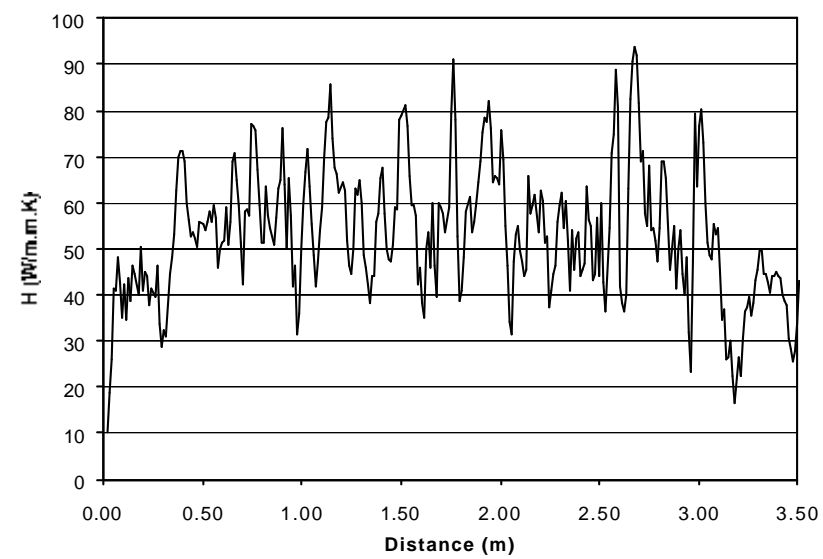

Figure 5. H values calculated from sensor data

\section{GENERATION OF THE PRODUCT DESCRIPTION}

As identified in the previous section the data required for each thermal node within the product model are its effective inplane conductivity, both in the $\mathrm{X}$ and $\mathrm{Y}$ directions, its thermal mass, average emissivity, and the convection area. For an area of the PCB unpopulated by tracks or components this data is simple to calculate. For a node with a significant density of conductive tracks, but no components, the additional contribution of the tracks to the thermal conductivity of the node must be taken into account. This additional thermal conductivity will be principally in the direction of the tracks, with little effect perpendicular to them. The additional thermal mass of the tracks should also be included, although it will have a very small effect unless the board has a large number of layers. Provided the board has a solder mask, which substantially increases the emissivity of tracks, then the emissivity is unlikely to be significantly affected by the presence of tracks unless there is a large unbroken area of copper. The convection area will be the same as the nodal plan area.

Where an area of the PCB is populated with components, calculation of the nodal properties is slightly more complex and the following modifications to the bare PCB properties must be made:
Conductivity: Components much smaller than the element size, such as ceramic chip capacitors and resistors, will have little effect on conductivity and can be safely ignored. Larger components, particularly those with a metal lead-frame, will however have a significant effect on the local in-plane thermal conductivity. An effective thermal conductivity was therefore calculated for each of the IC packages, taking into account the relative thickness of the lead-frame and package body. The thermal conductivity of each node under an IC was then modified taking into account the proportion of its area covered by the IC.

Thermal mass: The additional thermal mass of an individual component is the product of its volume, density and SHC and the total thermal mass of a node is therefore the sum of the PCB thermal mass and the individual component thermal masses. The components were however weighed so their volume and density did not have to be measured. Any component lying on the boundary of two or more elements was simply split between them in proportion to the component area within each element.

Emissivity: As noted in the previous section an accurate calculation of the effective emissivity of a node is quite complex. In most modern reflow ovens only a small proportion of the heat transfer is by radiative heat transfer and obtaining a precise value for the emissivity is therefore less important. Based on this it was decided to simply calculate nodal emissivity based on the (plan) area we ighted average of the emissivities of the materials present within an element.

Convection area: The addition of components to a thermal node will increase the total surface area available to convective heat transfer. If the components sit close to the PCB, then there will be little airflow under the components and it can be assumed that the bottom of the component and the area of PCB underneath it only play a small part in convective heat transfer. The additional convection area due to a component is therefore only the area of its sides, i.e. the component height multiplied by the length of its perimeter. Where a component overlies an element border this additional surface area is split between the elements as for its thermal mass.

\section{The test PCB}

Figure 6 shows the test board used in the modelling trials, which is about $20 \mathrm{~cm}$ by $15 \mathrm{~cm}$ and has a total of 37 components, including one 44 pin PLCC, and a mix of SO and chip components. In order to test the model a relatively coarse mesh of 20 by 15 elements was used, resulting in a total of 300 thermal nodes. The materials properties used in setting up the model of the test board are listed in table 2. Ideally the product description would be generated directly from the CAD data, but in order to test the new modelling approach this data was generated for an existing test PCB design using a spreadsheet. Data entry for the test board proved extremely time consuming, but testing of the significance of various parameters was then very straightforward. 


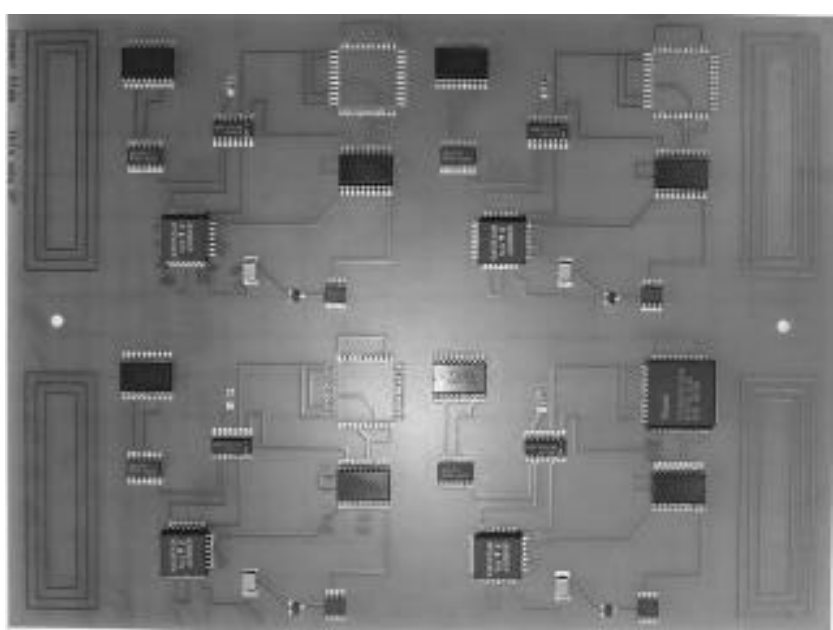

Figure 6. The test PCB

Table 2. Materials properties used for the modelling trial

\begin{tabular}{ccccc}
\hline Material & Emissivity & $\begin{array}{c}\text { Density } \\
(\mathrm{kg} / \mathrm{m} 3)\end{array}$ & $\begin{array}{c}\text { S.H.C. } \\
(\mathrm{J} / \mathrm{kg} . \mathrm{K})\end{array}$ & $\begin{array}{c}\text { Effective K } \\
(\mathrm{W} / \mathrm{m} . \mathrm{K})\end{array}$ \\
\hline $\begin{array}{c}\text { PCB } \\
\text { laminate } \\
\begin{array}{c}\text { Chip } \\
\text { capacitor }\end{array}\end{array}$ & 0.90 & 1885 & 1100 & 0.31 \\
$\begin{array}{c}\text { Chip } \\
\text { resistor } \\
\text { Black }\end{array}$ & 0.94 & - & 765 & - \\
Epoxy & 1.00 & - & 850 & 2.1 to 3.2 \\
\hline
\end{tabular}

\section{RESULTS}

\section{Experimental data acquisition}

A sample of the test board shown in Figure 6 had thermocouples attached to an 1812 capacitor, a 20 pin SOIC, a 28 pin PLCC and to both the corner and centre of the 44 pin PLCC. To reduce thermal degradation of the test board, and any consequent changes in its thermal properties, the reflow furnace was set to a slightly cooler profile than would typically be used in production. Figure 7 shows the resulting time temperature profiles for the five thermocouples.

\section{Modelling results}

The model was run using the measured $\mathrm{H}$ data as presented in Figure 5, together with the predicted temperature/distance profile shown in Figure 5. Figure 8 shows the predicted distribution of temperatures in the PCB at a particular instant in time during the reflow process, and Figures 9 and 10 show a comparison of the predicted and measured time/temperature profiles for the five thermocouple locations. From figures 9 and 10 it can be seen that there is excellent agreement between the model and experimental results throughout the entire reflow process. The average difference in peak temperature between model and experiment was $3.5^{\circ} \mathrm{C}$ and the maximum difference was less than $5^{\circ} \mathrm{C}$. The analysis time was $0.44 \mathrm{~s}$ on a $300 \mathrm{MHz}$ Intel Pentium processor with $64 \mathrm{MB}$ of RAM.

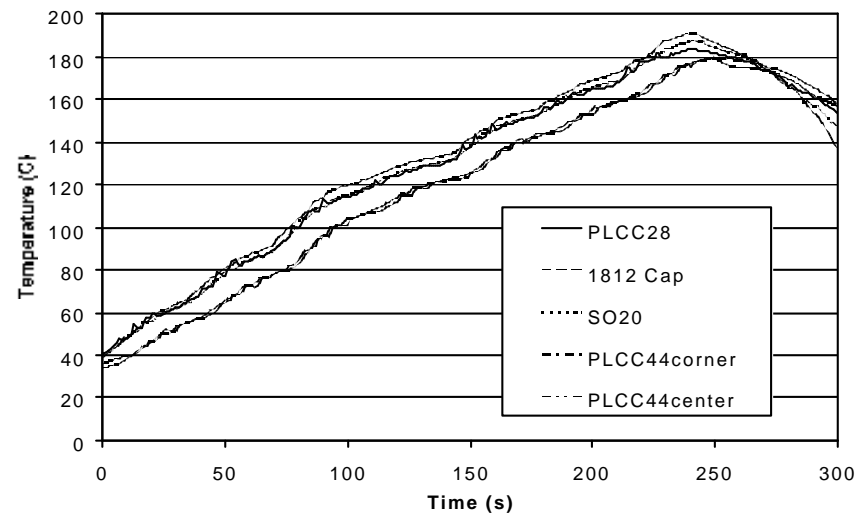

Figure 7. Time temperature profile of the test board

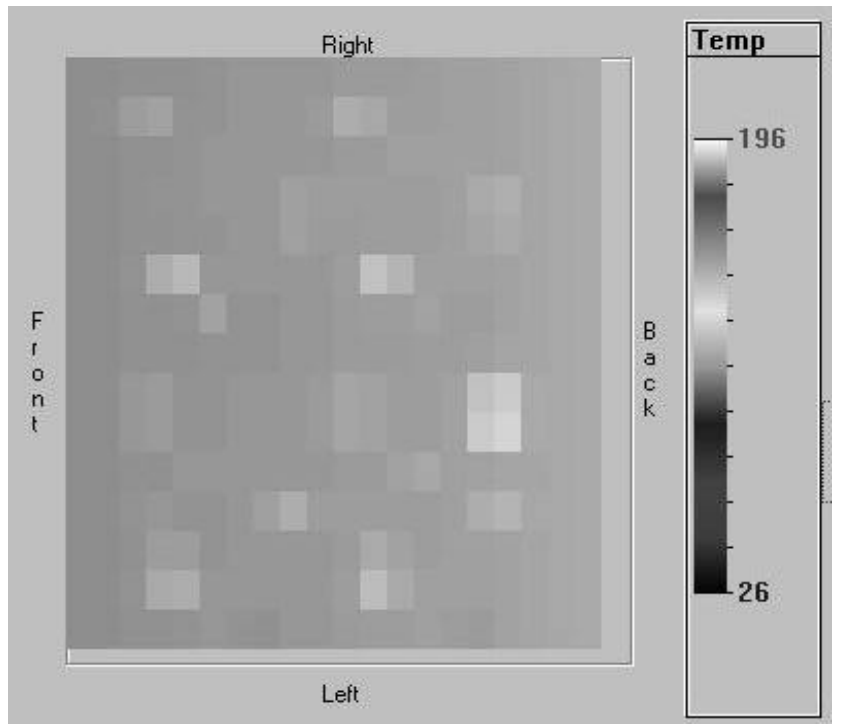

Figure 8. Predicted test PCB temperature distribution

\section{CONCLUSIONS}

It has been demonstrated that a very simple model of the reflow soldering process can provide extremely accurate predictions of the reflow profile for a given set of process settings. In this simulation process measurements are used to create a model which can predict the temperature at any point within the reflow furnace as a function of the process settings. These temperatures are then used as boundary conditions for a 2D model of the circuit board to be processed. This modelling approach greatly reduces the time required to create and run the simulation compared with models where boundary conditions are established from detailed process equipment geometry and either measurements or CFD predictions of the airflow velocities. Further work is required to test the limits of accuracy of the approach developed, both for other soldering furnaces, particularly those where heat transfer is IR dominant, and also for more complex PCB assemblies. In addition to its use in process optimisation during the new product introduction process, the modelling approach is simple enough to use during the PCB design stage to ensure compatibility of the design with available process hardware. 
The process data acquisition and modelling approach described here is probably also applicable to other thermal processes where significant variations in product thermal mass require product specific process optimisation, such as in paint curing, ceramic kilning processes and in the food processing industry.

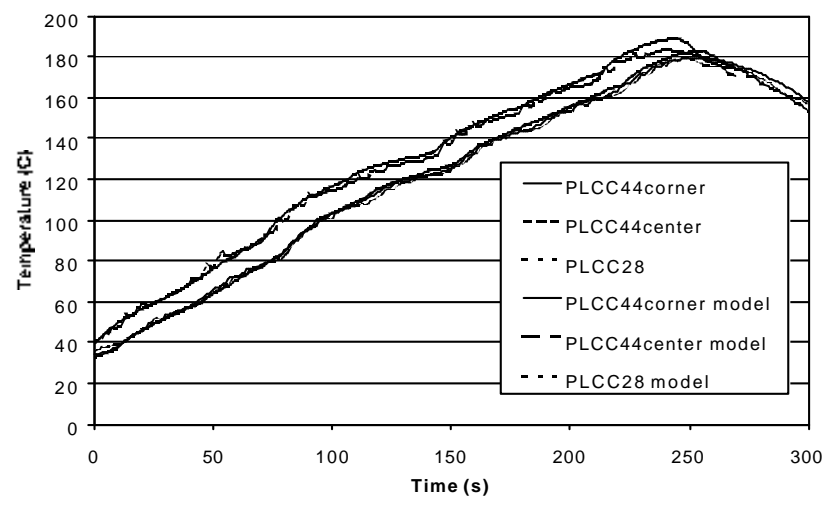

(a) Whole profile

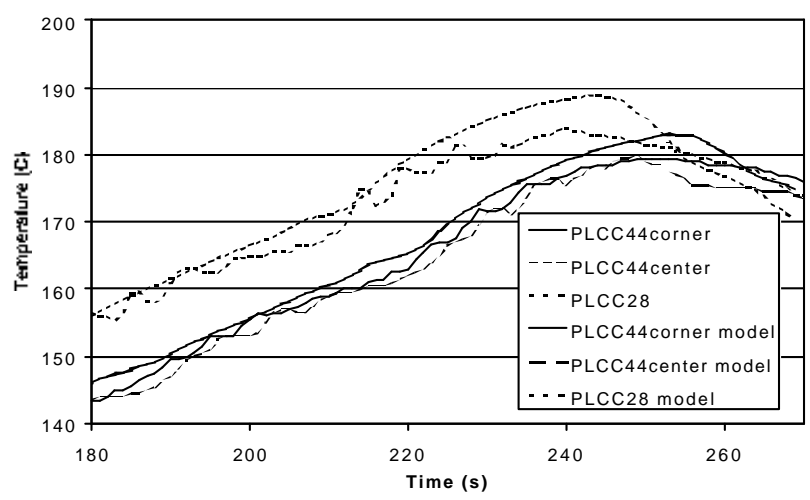

(b) Near reflow

Figure 10. Comparison of measured and predicted temperature profiles for the QFP components

\section{ACKNOWLEDGMENTS}

The author gratefully acknowledges the financial and technical support of Datapaq Limited.

\section{REFERENCES}

[1] Whalley, D. C. Williams D. J. and Conway, P. P., "Thermal modelling of temperature development during the reflow soldering of SMD Assemblies", Proceedings of the 6th ISHM International Microelectronics Conference, Tokyo, May 1990, pp385-394

[2] Whalley, D. C., Ogunjimi, A. O., Conway, P. P. and Williams, D. J., "The Process Modelling of the Inf ra-red Reflow Soldering of Printed Circuit Board Assemblies", Journal of Electronics Manufacture, Vol. 2, No.1, 1992, pp 23-29, ISSN 0960-3131

[3] Sarvar, F. and Conway, P. P., "Effective Modelling of the Reflow Soldering Process: Basis, Construction and Operation of a Process Model", IEEE Transactions on Components, Packaging and Manufacturing Technology Part C: Manufacture, Vol. 21, No. 2, 1998, pp 126-133, ISSN 10834400

[4] Eftychiou, M. A., Bergman, T. L. and Masada, G. Y., ”A detailed thermal model of the infrared reflow soldering process", ASME Journal of Electronic Packaging, vol. 115, 1993, pp. 55-62

[5] Kim, M. R., Choi, Y. K., Lee, G. B., Chung, I. Y. and Kim, J. D., "Thermal investigation of an infrared reflow furnace with a convection fan", Inter-Society Conference on Thermal Phenomena in Electronic Systems, 1996. I-THERM, pp 211 216

[6] H. Yu and J. Kivilahti "CFD Modelling of the Flow Field Inside a Reflow Oven" Soldering and Surface Mount Technology, Vol. 14, No. 1, March 2002, pp 38-44

[7] Hurst, A.I. and Pulko, S. H., "Modelling the transient thermal experience of large pieces of vitreous china ware during firing", Proceedings of the IASTED International Conference on Applied Modelling and Simulation, Anaheim, CA, USA, 1993, pp.150-153

[8] D. C. Whalley and S. M. Hyslop "A Simplified Model of the Reflow Soldering Process” Soldering and Surface Mount Technology, Vol. 14, No. 1, March 2002, pp 30-37

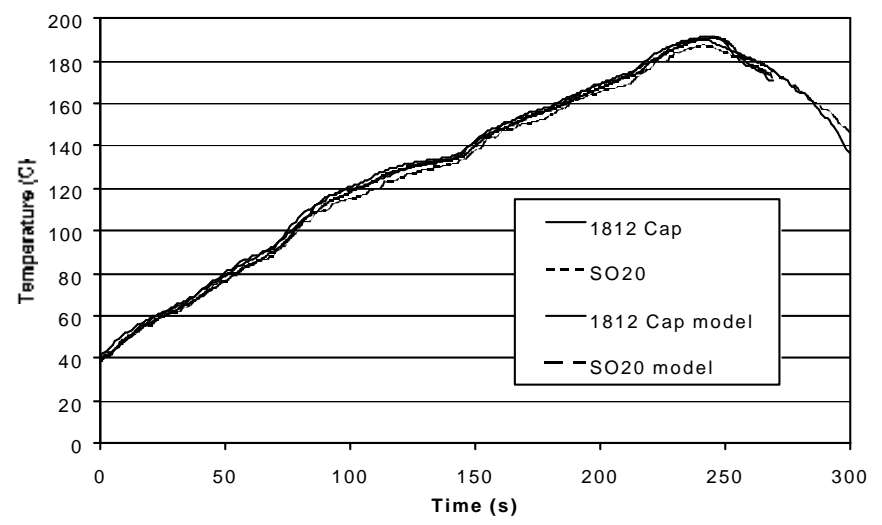

(a) Whole profile

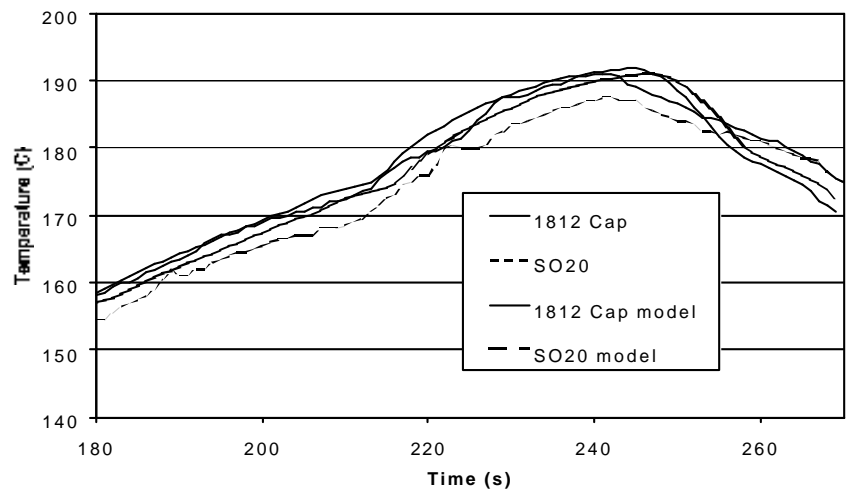

(b) Near reflow

Figure 11. Comparison of measured and predicted temperature profiles for the 1812 capacitor and SOIC 